\title{
Journal of the Arkansas Academy of Science
}

\section{Using infrared imagery to estimate white-tailed deer populations on the Pine Bluff Arsenal}

\author{
D. M. Techentin \\ University of Arkansas at Monticello, techentin@uamont.edu
}

E. S. Boyd

University of Arkansas at Monticello

W. E. Sparks

Pine Bluff Arsenal

R. E. Kissell Jr.

University of Arkansas at Monticello

Follow this and additional works at: https://scholarworks.uark.edu/jaas

Part of the Zoology Commons

\section{Recommended Citation}

Techentin, D. M.; Boyd, E. S.; Sparks, W. E.; and Kissell, R. E. Jr. (2012) "Using infrared imagery to estimate white-tailed deer populations on the Pine Bluff Arsenal," Journal of the Arkansas Academy of Science: Vol. 66 , Article 27.

DOI: https://doi.org/10.54119/jaas.2012.6620

Available at: https://scholarworks.uark.edu/jaas/vol66/iss1/27

This article is available for use under the Creative Commons license: Attribution-NoDerivatives 4.0 International (CC BY-ND 4.0). Users are able to read, download, copy, print, distribute, search, link to the full texts of these articles, or use them for any other lawful purpose, without asking prior permission from the publisher or the author.

This Article is brought to you for free and open access by ScholarWorks@UARK. It has been accepted for inclusion in Journal of the Arkansas Academy of Science by an authorized editor of ScholarWorks@UARK. For more information, please contact scholar@uark.edu. 


\title{
Using Infrared Imagery to Estimate White-Tailed Deer Populations on the Pine Bluff Arsenal
}

\author{
D.M. Techentin ${ }^{1}$, E.S. Boyd ${ }^{1}$, W.E. Sparks ${ }^{2}$, and R.E. Kissell, Jr. ${ }^{1}$ \\ ${ }^{1}$ University of Arkansas at Monticello, School of Forest Resources, Monticello, AR 71656, \\ ${ }^{2}$ Department of Defense, Pine Bluff Arsenal, White Hall, AR 71602
}

Correspondence: techentin@uamont.edu

\begin{abstract}
Military installations present unique challenges to natural resource managers managing wildlife populations. For those species that are hunted or trapped, it is important to provide data to these installations for achieving sustainable harvests. Pine Bluff Arsenal (PBA), a military installation in southeastern Arkansas, manages for a host of wildlife species including white-tailed deer (Odocoileus virginianus). However, baseline data regarding population size for deer are lacking. We used infrared technology and distance sampling to estimate the size of the winter, post-harvest deer population on PBA. We identified 9 competing models. The best model provided an estimate of density of 0.245 deer/ha $(\mathrm{CV}=$ $43 \%$ ) with a mean group size of 3.3 deer. This density estimate will serve as a baseline value for evaluating future management actions.
\end{abstract}

\section{Introduction}

Natural resource management is important to military installations and supports the military mission (Campbell et al. 1997). Forestry programs on military installations are often self-sufficient, providing revenue from timber sales, areas for military training, and protection of infrastructure through the removal of high-risk trees. Wildlife management practices, unlike forestry, often are not self-sufficient but rely on revenue from hunting and fishing licenses. Although natural resource management supports the military mission overall, it is restricted by military policies (Campbell et al. 1997). Open areas surrounding buildings have grass height restrictions and cannot be manipulated for wildlife habitat. Secure areas, surrounded by high fences topped with barbed wire, are off-limits to hunters and limit wildlife movement. Some species, such as white-tailed deer (Odocoileus virginianus), can jump over high fences, but are occasionally mortally injured in the attempt (Campbell et al. 1997).
After the terrorist attack of 9-11-2001, many military installations were closed to hunting (personal communication, WES). Unmanaged deer populations can reach high densities resulting in economic losses to forests, increase deer-vehicle collisions, and facilitate the spread of both human and animal diseases (Côté et al. 2004). Consequently, high harvest rates were needed to reduce population density when deer hunting was allowed again (personal communication, WES).

Deer populations on military installations have been studied in a variety of ways. Dinkines et al. (1992) assessed causes of mortality on the Fort Sill Military Reservation, a field artillery and missile training center in Oklahoma, finding that sportsmen accounted for $28 \%$ of deer mortality. Weckerly et al. (2005) assessed hunter effort-harvest size relationships on the Milan Army Ammunition Plant (MLAAP) in Tennessee, finding that hunters harvested deer with less effort at MLAAP than other areas. Although there have been studies conducted on deer mortality and harvest, there is a lack of published research relative to estimating density.

There are several methods used to index deer populations including spot light counts, thermal imager counts, drive counts, and aerial counts (Lancia et al. 2005) Indices require knowing a detection probability to provide reliable population size estimates (Lancia et al. 2005) and follows the relationship:

$$
\widehat{N}=\frac{C}{\beta^{\prime}}
$$

where $\widehat{N}$ is the population estimate, $\mathrm{C}$ is the count, and $\beta$ is the detection probability. Detection probabilities, however, are affected by other factors related to the observer, the environment, and the species itself. As a result, indices are not reliable and population estimates should be used (Anderson 2001).

There are several methods used to estimate population size including mark-recapture, doublesampling, and distance sampling. Mark-recapture and double-sampling are typically more expensive than distance sampling, however. Distance sampling is a 
widely applied, reliable and accepted method used to provide population estimates (Gill et al. 1997, Buckland et al. 2001).

Reliable information relating to population size over time is necessary to assess trends of population growth rates. Since 2009, observations of does with two fawns have been rare occurrences on the Pine Bluff Arsenal (PBA, personal communication, WES). Harvest reports from the 2009-2010 hunting season on PBA indicated that the age structure of the deer population was heavily skewed toward older does (unpublished data). These indications have raised concerns about the population density and structure. Harvest data can provide information on population structure, but there are no data in relation to density and harvest as of yet.

The purpose of this study was to establish a baseline population estimate for white-tailed deer on the PBA to develop a management plan for reaching and maintaining a target population size.

\section{Materials and Methods}

\section{Study Area}

The study area was on the PBA, located in Jefferson County, Arkansas, USA. It is bounded on the east by the Arkansas River, on the north by the National Toxicological Research Center, and on the west and south by private land (Figure 1). PBA is about 5440 ha in size. There are over $200 \mathrm{~km}$ of roads dissecting the arsenal. Elevation ranges from 59.4 to $103.6 \mathrm{~m}$ above sea level and gradually slopes down toward the Arkansas River. The mean annual temperature was $16.9^{\circ} \mathrm{C}$ and the mean monthly winter precipitation was $13.5 \mathrm{~cm}$.

PBA is in the Mississippi Alluvial and the West Gulf Coastal Plains and is dominated by eastern cottonwood (Populus deltoids), box elder (Acer negundo), hickory (Carya spp.), oak (Quercus spp), bald cypress (Taxodium distichum), loblolly pine (Pinus taeda), and river birch (Betula nigra) (Campbell et al. 1997). Additional vegetation in the understory includes ironwood (Carpinus caroliniana), persimmon (Diospyros virginiana), and privet (Ligustrum sinense). Wetlands are dominated by black willow (Salix nigra) and green ash (Fraxinus pennsylvanica), with a buttonbush (Cephalanthus occidentalis) shrub under story. Grassland areas are dominated by little bluestem (Andropogon scoparius), panic grass (Panicum anceps), velvet panic (Panicum scoparium), grassleaved golden aster (Heterotheca graminifolia), and hoary pea (Tephrosia onobrychoides). Soils are loamy

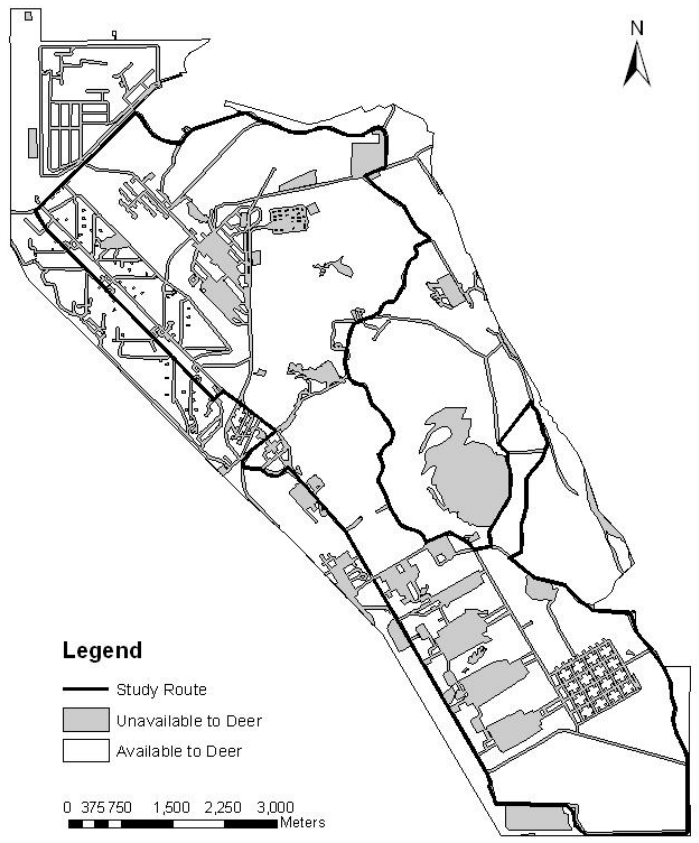

Figure 1. Boundary of Pine Bluff Arsenal, Jefferson County, Arkansas. Study route, areas unavailable to deer (i.e. industrial areas, parking lots, roads, bodies of water), and areas available to deer.

and sandy, primarily of Crevasse-Oklared, PhebaSavannah-Amy, Calloway-Grenada-Henry, and SaculSawyer-Savannah associations (Becker 1998).

Parts of the arsenal were developed into cover types that were not favorable for deer, including developed areas and water bodies. High fences topped with razor wire surrounded secure areas. Industrial areas, buildings, and parking lots made up $6.9 \%$ of the arsenal's area and did not provide habitat for deer. Bodies of water made up $3.6 \%$ of the arsenal's total area. Areas that were favorable for deer were managed by timber stand improvement harvests and prescribed burns. The property was divided into compartments that allowed no hunting, hunting with archery equipment only, or hunting with shotguns. The deer harvest season on PBA was concurrent with the statewide season.

\section{Surveys}

We established a $41.2 \mathrm{~km}$ long route that encompassed much of the arsenal (Figure 1). The route was subjectively placed to sample areas of high- and low-density roads and areas with different hunting restrictions. A total of 12 line transects, each sampled 8 times, was used. Line transects were each $1.7 \mathrm{~km}$ in length and spaced $1.7 \mathrm{~km}$ apart along the route. 
Transects established on roads incur a certain amount of bias (Buckland et al. 2001), but we believe the route chosen was representative of the arsenal due to the large number of roads present.

Each sampling period began one half hour after sunset. One observer stood in the back of a pickup truck that was driven $8-16 \mathrm{~km} / \mathrm{hr}$ and observed the landscape on one side of the road using a thermal imager (FLIR T620, Boston, MA). We alternated starting direction and observation side each sampling period to observe the same area but reduce time bias. When groups of deer were located, we used a spotlight to determine sex and age (fawn or adult) of the deer and measured the distance with a rangefinder (Bushnell Scout 1000 , Overland, KS) and bearing with a compass to the center of the group. We recorded time and the vehicle coordinates at each location with a Trimble (Geo-XM, Trimble, Sunnyvale) Global Positioning System (GPS) unit.

\section{Population Estimation}

We used a Geographic Information System (GIS) to estimate the total area available to deer. We subtracted the areas of several bodies of water and developed areas that were considered unavailable habitat. We also subtracted a $20 \mathrm{~m}$ buffer from all roads in the study area to eliminate the area associated with road bias. After subtracting the total area unavailable to deer as habitat from the total area of PBA, we determined there to be 4243 ha of habitat available to deer (Figure 1).

We used the vehicle location, distance and bearing to calculate locations of deer groups using trigonometry. We measured the perpendicular distance from each deer location to the transect using GIS.

We used Program DISTANCE 6.0 (Buckland et al. 2001) to estimate deer density. We set the sampling fraction to 0.5 because we only sampled one side of the transect lines on each survey. We used the following models (key function/series expansion) because of their robustness as recommended by Buckland et al. (2001) to estimate density: half normal/cosine, half normal/hermite polynomial, half normal/simple polynomial, uniform/cosine, uniform/hermite polynomial, uniform/simple polynomial, hazardrate/cosine, hazard-rate/hermite polynomial, and hazard-rate/simple polynomial. We used size-biased regression models to eliminate a dependence of detection probability on cluster size. We ran all models with 5\% right-truncation. Initial analyses indicated a trough in observations near the line (Figure 2a). To address the trough, we conducted two separate analyses following the methods of Ward et al. (2004). In addition to right-truncating the data, we also eliminated the trough near zero by left-truncating at 20 $\mathrm{m}$ and rescaling the data. Second, we pooled data into distance categories that accommodated the trough such that distance sampling could be employed. We did this knowing that the former approach results in overestimation of density and the latter approach results in underestimation of density. We selected the best model based on the minimum Akaike's Information Criterion with a correction for small sample sizes AIC $_{C}$; Akaike 1973, Buckland et al. 2001). We calculated density estimates, effective strip width (ESW; the distance from the line for which an equal number of animals are detected as are missed; Buckland et al. 2001) upper and lower $95 \%$ confidence levels for densities, goodness of fit (GOF) statistics, coefficients of variation, and weight for each model. Population size was based on 4243 ha of available habitat (Figure 1) and the estimated population density.

\section{Results}

A total of $200.7 \mathrm{~km}$ was surveyed on 8 nights from 27 January to 17 February 2012. A total of 98 groups of deer was detected, with a mean group size of 3.3 deer (Table 1).

Table 1. Summary of white-tailed deer group sizes observed during thermal imager surveys at Pine Bluff Arsenal during January and February 2012.

\begin{tabular}{lcccc}
\hline & & & \multicolumn{2}{c}{ Group Size } \\
\cline { 4 - 5 } Date & \# of & \# of & & \\
Groups & Deer & Mean & SE \\
\hline 27-Jan & 10 & 27 & 2.7 & 0.52 \\
28-Jan & 7 & 21 & 3.0 & 0.54 \\
30-Jan & 16 & 54 & 3.4 & 0.52 \\
4-Feb & 9 & 23 & 2.6 & 0.67 \\
6-Feb & 10 & 24 & 2.4 & 0.37 \\
11-Feb & 21 & 94 & 4.5 & 0.80 \\
16-Feb & 9 & 30 & 3.3 & 0.78 \\
17-Feb & 16 & 47 & 2.9 & 0.25 \\
Total & $\mathbf{9 8}$ & $\mathbf{3 2 0}$ & $\mathbf{3 . 3}$ & $\mathbf{0 . 2 3}$ \\
\hline
\end{tabular}

Of the 9 models examined, 4 were found to be competing models (i.e., $\mathrm{AIC}_{\mathrm{C}} \leq 2.0$ ) in each analysis (Table 2). For the right-truncation, the uniform key function with a simple polynomial adjustment modeled the data best (Figure 2b), the detection rate ranged 
from 0.58 to 0.73 , the ESW was $93.6 \mathrm{~m}$, the density estimate was 0.170 deer/ha $(\mathrm{CV}=43 \%, 95 \% \mathrm{CI}=$ $0.170-0.414)$, and the estimated population size was 722 deer $(95 \% \mathrm{CI}=297-1756)$. For the right- and lefttruncated analysis, the half normal key function modeled the data best (Figure 2c). The detection rate ranged from 0.38 to 0.53 , the ESW was $63.8 \mathrm{~m}$, the density estimate was 0.245 deer/ha $(\mathrm{CV}=43 \%, 95 \%$ $\mathrm{CI}=0.101-0.594)$, and the estimated population size was 1040 deer $(95 \% \mathrm{CI}=429-2521)$.

\section{Discussion}

Management goals dictate the desired population density of exploited populations. Most work examining the effect of deer density on vegetation or bird populations has been conducted in the northeast or upper mid-west of the United States (deCalesta 1994, Augustine et al. 1998, McShea and Rappole 2000). For example, Augustine et al. (1998) found deer in southeastern Minnesota should be managed at densities
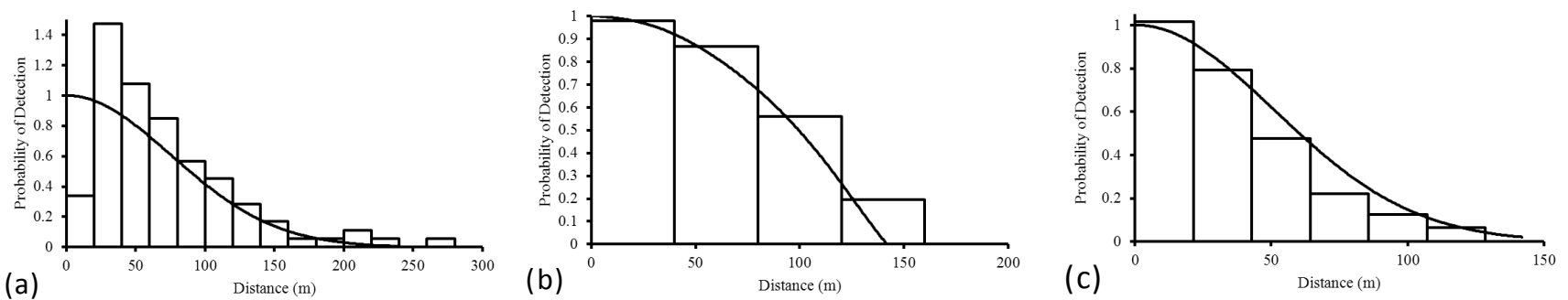

Figure 2. Detection probability plots for white-tailed deer using forward-looking infrared survey data collected at Pine Bluff Arsenal during Janurary and February 2012. Three models are shown using alternative truncation methods. The trough present in a model without any truncation is shown in (a), 5\% right-truncation only is shown in (b), and 5\% right-truncation and left-truncation with rescaling is shown in (c).

Table 2. Distance sampling results for white-tailed deer using forward-looking infrared survey data collected at Pine Bluff Arsenal during January and February 2012.

\section{Density (deer/ha)}

\begin{tabular}{|c|c|c|c|c|c|c|c|c|c|}
\hline Model $^{\mathrm{a}}$ & $\mathrm{AIC}_{\mathrm{C}}^{\mathrm{b}}$ & $\Delta \mathrm{AIC}$ & $\mathbf{L C L}^{\mathrm{c}}$ & Estimate & $\mathbf{U} \mathbf{C L}^{\mathrm{d}}$ & $\begin{array}{c}\text { Detection } \\
\text { Rate }\end{array}$ & $\begin{array}{c}\mathbf{G O F}^{\mathrm{e}} \\
\text { p-value }\end{array}$ & $\mathbf{C V}^{\mathrm{f}}$ & Weight $^{\mathrm{g}}$ \\
\hline \multicolumn{10}{|c|}{ Right-truncation } \\
\hline USP & 236.31 & 0.00 & 0.070 & 0.170 & 0.414 & 0.650 & 0.972 & 0.425 & 0.1925 \\
\hline UHP & 236.51 & 0.20 & 0.068 & 0.166 & 0.405 & 0.667 & 0.883 & 0.425 & 0.2126 \\
\hline $\mathrm{HN}$ & 237.05 & 0.74 & 0.073 & 0.178 & 0.437 & 0.594 & 0.673 & 0.432 & 0.2788 \\
\hline $\mathrm{UC}$ & 237.30 & 0.99 & 0.075 & 0.183 & 0.445 & 0.581 & 0.588 & 0.445 & 0.3161 \\
\hline \multicolumn{10}{|c|}{ Right- and left-truncation } \\
\hline $\mathrm{HN}$ & 253.05 & 0.00 & 0.101 & 0.245 & 0.549 & 0.449 & 0.880 & 0.426 & 0.1376 \\
\hline $\mathrm{UC}$ & 254.46 & 1.42 & 0.105 & 0.254 & 0.618 & 0.431 & 0.983 & 0.428 & 0.2794 \\
\hline HNC & 254.53 & 1.48 & 0.108 & 0.265 & 0.652 & 0.410 & 0.909 & 0.439 & 0.2888 \\
\hline HR & 254.57 & 1.52 & 0.100 & 0.246 & 0.604 & 0.458 & 0.967 & 0.436 & 0.2942 \\
\hline
\end{tabular}

${ }^{\text {a }}$ Models included USP = Uniform key function with a simple polynomial adjustment, UHP = Uniform key function with a hermite polynomial adjustment, HN = Half normal key function, $\mathrm{UC}=$ Uniform key function with a cosine adjustment, HNC = Half normal key function with a cosine adjustment, and HR = Hazard-rate key function.

${ }^{\mathrm{b}} \mathrm{AIC}_{\mathrm{C}}=$ Akaike information criterion value corrected for small sample size.

${ }^{\mathrm{c}} \mathrm{LCL}=$ Lower confidence limit $(95 \%)$.

${ }^{\mathrm{d}} \mathrm{UCL}=$ Upper confidence limit (95\%).

${ }^{\mathrm{e}} \mathrm{GOF}=$ Goodness-of-fit.

${ }^{\mathrm{f}} \mathrm{CV}=$ Coefficient of variation.

${ }^{\mathrm{g}}$ Weight based on AIC values. 
lower than $0.075 \mathrm{deer} / \mathrm{ha}$ or $0.149 \mathrm{deer} / \mathrm{ha}$, depending on the stable state for forests to recover from browsing. Augustine et al. (1998) found that the grazing of deer in highly dense populations (i.e., $0.149 \mathrm{deer} / \mathrm{ha}$ ) can extirpate populations of wood nettle (Laportea canadensis), while low deer densities (i.e., 0.075 deer/ha) allow persistence of wood nettles, and intermediate deer densities will either extirpate wood nettles or allow them to persist, depending on whether they are in low or high abundance initially. As another example, Allegheny hardwood stands being managed for songbirds should have deer densities maintained under 1 deer/12.7 ha or 1 deer/6.7 ha because both densities represent a threshold over which songbird species richness and abundance decline due to lack of vegetation (deCalesta 1994). The current point estimate of deer density on PBA is 0.24 deer/ha and is in excess, though only slightly, of that recommended to maintain vegetation or bird densities (deCalesta 1994, Augustine et al. 1998). Functionally, deer can reduce composition and abundance of bird and vegetation species on a site (McShea and Rappole 2000). The same impact is expected on other sites, such as PBA. Because differences in locations exist, however, the deer density required to make those changes likely varies also.

The density of deer on PBA was intermediate compared to the reported densities of deer at other locations in eastern Arkansas. Cutoff Creek Wildlife Management Area in Drew County, Lakeside Hunting Club in St. Francis County, and Wingmead Farms in Prairie County had lower reported densities (0.104 deer/ha; 0.056 deer/ha; 0.233 deer/ha, respectively, Kissell and Nimmo 2011) than PBA. Choctaw Island Wildlife Management Area in Desha County had a higher reported density (0.313 deer/ha) than PBA. Choctaw Island, Lakeside Hunting Club and Wingmead Farms were not heavily hunted prior to the estimates being provided and each had agricultural crops available to deer as a source of forage; Cutoff Creek, a predominately bottomland hardwood area, along with Lakeside Hunting Club were prone to flooding and this likely affected population sizes. Though PBA does not have agricultural crops available, the population is capable of reaching high densities.

The initial analysis showed both a trough close to zero and few observations at the right-hand tail of the detection curve. The right-truncation was necessary to eliminate outliers and improve the model fit. The trough was problematic because there should be a "shoulder" at zero distance from the line, where the highest probability of sighting an animal should exist (Figure 2a; Buckland et al. 2001). As Ward et al. (2004) did, we left-truncated at $20 \mathrm{~m}$ and rescaled the data to eliminate the trough. The left truncation only removed nine clusters. If there had been more clusters near the transect, it may have been possible to estimate near-road density.

Our best model had a $\mathrm{CV}=0.425$, a level exceeding that required for accurate management (Skalski et al. 2005). The precision of density estimates depends upon the number of replicates with a minimum of 10-20 recommended (Buckland et al. 2001). A minimum of 60-80 observations is recommended by Buckland et al. (2001) to provide a reliable estimate of density. We included 93 observations after right-truncation and 85 after rightand left-truncation.

The thermal camera allowed us to detect deer even when vegetation obscured them from sight. It also lessened the probability of disturbing the deer because groups were located and recorded before we were perpendicular to them. Spotlight surveys are less expensive than infrared surveys, but detectability is often lower (Tappe and Kissell 2006). In a comparison of spotlight and thermal infrared imaging surveys, Tappe and Kissell (2006) detected 2.4 times more groups and 3.4 times more deer using an infrared imager than a spotlight. It is more efficient for research and management purposes to use a method more capable of collecting data to estimate deer densities.

Three basic assumptions are required for distance sampling (Buckland et al. 2001). The first assumption is that all objects on the line were detected. Our data indicated a trough of distances near the line. The observed distances from the line may have been due to the behavior of the species in relation to the edge and/or the road. Deer may have demonstrated avoidance of the road due to traffic or were drawn to edge for foraging. Ward et al. (2004) noted the same issue with Roe deer (Capreolus capreolus). There is likely spatial variation in deer density across areas with edge, but the effect of how roads interact with edge is unknown.

The second assumption is that objects were detected at their initial locations. The thermal camera allowed us to detect deer from farther away, which allowed us to record their location without disturbing them. We did not observe movement by deer in response to the observers when first detected whether they were on the road or at a distance from the road. However, we were not aware of the behavior of the deer prior to detection so this assumption still stands.

\section{Journal of the Arkansas Academy of Science, Vol. 66, 2012


The third assumption, that measurements were exact, we believe was met. We used GPS units, compass bearings, and a rangefinder to determine deer locations and perpendicular distances were measured in a GIS. The spotlight was not bright enough to allow observers to use the rangefinder to find exact distances for the farthest groups, but the largest $5 \%$ of distance observations were truncated before analysis so they did not affect the data analysis in any way.

Before our survey began, the deer population was thought to be much larger. It was not unusual to see very large groups of deer in open areas. Seeing large groups in one area consistently led to the belief that there may have been 1000 or more deer on the arsenal. PBA's current deer density is similar to proposed target densities, but reducing the population would lower the density beneath thresholds for diversity. It would be beneficial to manage the deer at a lower density in the future if diversity of vegetation and vertebrates are a priority.

\section{Acknowledgements}

We would like to thank Pine Bluff Arsenal and individuals who helped us collect data, Clay Ferrell, PBA and Cody Williams, UAM.

\section{Literature Cited}

Akaike H. 1973. Information theory and an extension of the maximum likelihood principle. In: Petran, BN and F Csaaki, editors; International Symposium on Information Theory. Akadeemia (Kiadi, Budapest, Hungary). p 267-281.

Anderson DR. 2001. The need to get the basics right in wildlife field studies. Wildlife Society Bulletin 29(4):1294-1297.

Augustine DJ, LE Frelich and PA Jordan. 1998. Evidence for two alternate stable states in an ungulate grazing system. Ecological Applications 8:1260-1269.

Becker CM. 1998. Pine Bluff Arsenal Integrated Natural Resources Five Year Management Plan. Pine Bluff Arsenal, Pine Bluff, AR.

Buckland ST, DR Anderson, KP Burnham, JL Laake, DL Borchers and L Thomas. 2001. Introduction to distance sampling: estimating abundance of biological populations. Oxford University Press (Oxford, UK) 432 p.
Campbell J, CI Peacock and SA Walker. 1997. Final Report, Pine Bluff Arsenal. Survey of threatened and endangered plants, vegetation, and natural areas. Arkansas Field Office, The Nature Conservancy, Little Rock, AR.

Côté SD, TP Rooney, J Tremblay, C Dussault and DM Waller. 2004. Ecological impacts of deer overabundance. Annual Review of Ecology, Evolution, and Systematics 35:113-147

deCalesta DS 1994. Effect of white-tailed deer on songbirds within managed forests in Pennsylvania. Journal of Wildlife Management 58:711-718.

Dinkines WC, RL Lochmiller, WS Bartush, CA DeYoung, CW Qualls, Jr. and RW Rulton. 1992. Cause-specific mortality of white-tailed deer as influenced by military training activities in southwestern Oklahoma. Journal of Wildlife Diseases 28(3):391-399.

Gill RMA, ML Thomas and D Stocker. 1997. The use of portable thermal imaging for estimating deer population density in forest habitats. Journal of Applied Ecology 34:1273-1286.

Kissell RE and SK Nimmo. 2011. A technique to estimate white-tailed deer Odocoileus virginianus density using vertical-looking infrared imagery. Wildlife Biology 17:85-92.

Lancia RA, JD Nichols, KH Pollock and WL Kendall. 2005. In: C. E. Braun, editor. Estimating the number of animals in wildlife populations. Wildlife Techniques Manual, $6^{\text {th }}$ edition. The Wildlife Society (MD). p 106-153.

McShea WJ and JH Rappole. 2000. Managing the abundance and diversity of breeding bird populations through manipulations of deer populations. Conservation Biology 14:1161-1170.

Skalski JR, KE Ryding and JJ Millspaugh. 2005. Wildlife demography: Analysis of sex, age, and count data. Elsevier Academic Press (CA). 636 p.

Tappe PA and RE Kissell, Jr. 2006. Whitetailed deer density estimation using thermal infrared imaging. In: Bartoš, L, A Dušek, R Kotrba, J BartošováVíchová, editors. Advances in Deer Biology. PowerPrint, Provozovna (Prague). p 146-151.

Ward AI, PCL White and CH Critchley. 2004. Roe deer Capreolus capreolus behavior affects density estimates from distance sampling surveys. Mammal Review 34:315-319.

Weckerly FW, ML Kennedy and SW Stephenson. 2005. Hunter-effort-harvest-size relationships among hunt types of white-tailed deer. Wildlife Society Bulletin 33(4):1303-1311. 